\section{LESSON 49}

Envelope addressing

Use A4 paper flat with C4.

Use A5 paper or A4 paper folded into two with $\mathrm{C5}$.

Layout

Address

Forms of Address

In some offices, addresses are typed on labels for large packets and parcels.

Practise addressing envelopes

UNIT 13
The Post Office Guide tells all you need to know about envelope sizes and how to address envelopes. There are Post Office Preferred sizes for envelopes and in your Commerce or Office Practice lessons you should look them up. The usual sizes are C4 $(324 \times 229 \mathrm{~mm})$, C5 $(229 \times 162 \mathrm{~mm})$ and C6 $(162 \times 114 \mathrm{~mm})$.

Place the address parallel to the side of the envelope at least halfway down and towards the right. Type and underscore special instructions such as 'Private' or 'For the attention of', two spaces above the name of the addressee.

Each item should have a line to itself, but if the address must be shortened because of lack of space, the postal town and county may be typed on the same line. The postcode must have a line to itself and be the last line.

Type in single line spacing unless the envelope is a large one, when it may be better to type in double line spacing.

The address must contain: Name of addressee

Name or number of house
Street or road name
Town (Postal town in capital letters)
County (where necessary)
Postcode (always the last item)

Use the blocked style: it saves time. Set a margin where you want all the lines to start. The margin will depend on the size of the envelope you are using and the length of the longest line. The longest line should be roughly centred about the middle of the width of the envelope. Remember to start at least half way down the length of the envelope.

Always include the Courtesy title (Miss, Mrs., Mr., Snr., Jnr., and so on) when using a person's name. Abbreviations must be followed by a full stop.

Type a comma after every line except the last line, which is followed by a full stop. The Postcode must not be punctuated.

Never include a courtesy title when addressing business firms, unless you are addressing a person at that firm by name.

Leave one space after the full stop(s) following a person's initials, e.g., P. J D. Brown, Esq.,

Leave no space after the full stops in degrees, but leave a space between groups of degrees, e.g., Mr. J. P. Smith, B.Sc. or Mr. J. Smith, B.A., B.Sc.,

The letters Rev., which are short for Reverend, take the place of the courtesy title Mr. and Esq. Do not use both Mr. and Esq., when addressing a man.

Use a sheet of A6 paper $(148 \times 105 \mathrm{~mm})$ as your envelope. If you fold a sheet of A4 paper into 4 you can use the paper for 8 envelopes -4 on each side.

Type the following in the correct form.

1. R. Bowden, Esq., Il Orchard Lane, MANCHESTER. MAl 4OL

2. Yorkshire Wool Co. Ltd., 55 Lamb Lane, BRADFORD. BR6 7 EL

3. Christopher Wust, 56 Bolton Road, Southport. LA9 2SO

4. Mr. T. Good, Esq., 47 Sandy Lane, WALSALL, Staffs. WA3 4SL

5. Miss Jane Roberts, 57 High Street, Bude, Cornwall, CO9 8BU

6. Rev. P.Thew, Esq., 23 Dudley Road, BIRMINGHAM. BL7 2DR

7. Miss P Stubbs 56 Field Lane Shifnal Salop SAl 9SH Private

LESSON 49 